\title{
Associations of Angiotensin-Converting Enzyme Gene Insertion/Deletion (ACE Gene I/D) Polymorphism With Vitiligo: An Updated Systematic Review and Meta-Analysis
}

\author{
Mohammad Almohideb ${ }^{1}$ \\ 1. Dermatology, College of Medicine King Saud Bin Abdulaziz, University for Health Sciences, Riyadh, SAU
}

Corresponding author: Mohammad Almohideb, moalm20@gmail.com

\section{Abstract \\ Objective}

The objective of the article is to summarize the current evidence regarding the association between angiotensin-converting enzyme insertion/deletion (ACE I/D) gene polymorphism and vitiligo disease.

\section{Methods}

A computerized search was performed through four electronic databases (PubMed, Scopus, Cochrane Central Register of Controlled Trials [CENTRAL], and Web of Science) with the relevant keywords. Included studies comprised of papers examining the association of ACE gene polymorphisms with vitiligo. Data were pooled as an odds ratio (OR) in random- and fixed-effect models using the Mantel-Haenszel (M-H) method. Review Manager 5.3 software (clicktime.com, Inc., San Francisco, US) was utilized in the meta-analysis.

\section{Results}

Ten studies $(n=2,740)$ matching the inclusion criteria were included in the systematic review and metaanalysis. Results showed no significant difference between individuals carrying deletion/deletion (D/D) genotype and individuals with deletion/insertion (D/I) + insertion/insertion (I/I) genotypes in terms of vitiligo risk (odds ratio $[\mathrm{OR}]=1.13,95 \%$ confidence interval $[\mathrm{CI}]: 0.78$ to $1.64, \mathrm{p}=0.53$ ). However, vitiligo risk was higher in the individuals carrying the I/D genotype when compared with individuals with D/D + I/I genotypes ( $\mathrm{OR}=1.29,95 \% \mathrm{CI}$ : 1.10 to $1.52, \mathrm{p}=0.001)$. Moreover, the increased risk was observed in individuals carrying D/D when compared with I/I (OR=1.67, 95\% CI: 1.33 to 2.09 , $\mathrm{p}<0.0001)$. D allele was associated with significant risk when compared with the I allele (OR=1.29, $95 \%$ CI: 1.15 to $1.45, \mathrm{p}<0.0001)$.

\section{Conclusion}

Received 04/20/2020

Review began 04/28/2020 Review ended 05/09/2020 Published 05/10/2020

(c) Copyright 2020

Almohideb. This is an open access article distributed under the terms of the Creative Commons Attribution License CC-BY 4.0., which permits unrestricted use, distribution, and reproduction in any medium, provided the original author and source are credited.
The current evidence suggests that there is a significant association between ACE I/D gene polymorphism and vitiligo. These findings support the use of ACE polymorphism in the prediction of vitiligo as a biomarker.

Categories: Dermatology, Genetics

Keywords: ace, polymorphis, vitiligo, meta-analysis

\section{Introduction}

Vitiligo is a common, acquired, idiopathic, and progressive skin disorder characterized by loss of functional melanocytes and melanin from hair follicles and skin, which leads to one or more white patches of depigmented skin $[1,2]$. According to large population surveys, the estimated prevalence of vitiligo was 0.5$2 \%$ worldwide, which can reach $8.8 \%$ in some areas of Asia, such as in India [3].

Symmetrical and generalized distributions of depigmented skin are the most common presentation of the disease; however, segmental, non-segmental, focal, and mixed distributions are sporadically seen [4]. Despite the idiopathic nature of this disease, autoimmune responses, oxidative stress, and neural factors are the most common factors that are thought to play a role in its pathogenesis [5].

Many researchers identified several vitiligo susceptibility genes that regulate the immune system, such as cytotoxic T-lymphocyte antigen-4 (CTLA4), human leukocyte antigens (HLA), and NACHT leucine-repeat protein 1 [6-8]. One of the important genes is the angiotensin-converting enzyme (ACE) gene, which regulates vascular physiology and participates in the immune system. The D allele of the ACE gene insertion/deletion (I/D) polymorphism was found to be associated with vitiligo $[9,10]$. 
However, the results of the previous studies showed partial disagreement due to multiple factors such as small sample size, racial/ethnic differences, and minor polymorphism effect on vitiligo risk. Therefore, in this systematic review and meta-analysis, the aim was to summarize and investigate the current evidence regarding the association between vitiligo and ACE gene I/D polymorphism.

\section{Materials And Methods}

This systematic review and meta-analysis followed the Preferred Reporting Items for Systematic Review and Meta-Analysis (PRISMA) checklist [11].

\section{Search strategy}

Computerized searches in four databases (PubMed, Scopus, Web of Science, and Cochrane Central Register of Controlled Trials [CENTRAL]) were done. Research records were exported into EndNote Windows version X8 (Clarivate Analytics, Philadelphia, US). Articles were identified using the relevant search keywords "Vitiligo", "gene polymorphism”, “Angiotensin-converting enzyme”, “ACE”, and “I/D.”

\section{Selection of studies}

Retrieved records were screened in two steps: 1) title and abstract screening, and 2) full-text articles screening for eligibility to meta-analysis. Multiple publications/reports from the same study were excluded, and the latest publication with complete data was considered for meta-analysis.

\section{Inclusion and exclusion criteria}

Included studies examined the association of ACE gene polymorphisms with vitiligo. Eligible studies determined the distribution of alleles and or genotypes for the ACE gene $/ D$ polymorphism in unrelated cases with vitiligo and in unrelated controls without vitiligo. Studies of other ACE polymorphisms in relation to vitiligo were excluded. Utilized data was from published papers and not from conference abstracts, case reports, or review articles. Moreover, studies were excluded in the following conditions: studies with a population encompassing healthy volunteers, studies with non-reliable data for extraction and analysis, thesis and conference papers, and animal models.

\section{Data extraction}

Two independent reviewers extracted the data using an offline data extraction form (Microsoft Excel 2016, windows version). The extracted data include the following: characters of populations and study design (study design, the country, the ethnicity of the study population, the number of cases and controls, demographics of the patients and controls, and the distribution of ACE LD genotypes in the case and control groups).

\section{Data synthesis and heterogeneity}

Heterogeneity was assessed and interpreted according to the Cochrane Handbook for Systematic Reviews and Meta-analysis recommendations, by visual inspection of the forest plots and measured by I-square and Chi-square tests [12]. An alpha level (for Chi-square test) below 0.1 indicates significant heterogeneity, and the I-square test is interpreted as follows: $0 \%$ to $40 \%$ might not be important; $30 \%$ to $60 \%$ may represent moderate heterogeneity; $50 \%$ to $90 \%$ may represent substantial heterogeneity. In the case of significant heterogeneity, the random-effects model was utilized. Otherwise, the fixed-effect model was employed. Heterogeneity was resolved using Cochrane's Leave-one-out method [13].

The Mantel-Haenszel method was chosen above the Peto method due to the relatively few obtained studies with different sample sizes and were not investigating a rare outcome. Studies included subjects from different ethnicities; therefore, a random-effects model was provided in addition to the fixed effects model to examine the change in variability in case of failure to assume that the true effect size was equal across all studies. The odds ratio was pooled in the random effect model meta-analysis (Der-Simonian Liard method). Statistical analyses were performed using Review Manager 5.3 (clicktime.com, Inc., San Francisco, US).

\section{Subgroup analysis}

A subgroup analysis was performed according to the following: 1) ethnicity of the included population (Egyptian, Asian, whether Korean or Indian, and European); 2) vitiligo type (generalized, focal, segmental, and non-segmental); and 3) association with other autoimmune diseases.

\section{Results}

\section{Search results}

Four databases were searched (PubMed, Scopus, Web of Science, and CENTRAL) and records were exported into EndNote. After removing duplicates, 450 unique records are retrieved and ready for screening against the inclusion and exclusion criteria. Title and abstract screening led to exclusion of 412 studies and the 


\section{Cureus}

finding of 38 potential full-text articles that can be included. After the full-text screening, ten studies $(n=2,740)$ matched the inclusion and exclusion eligibility criteria for this systematic review and metaanalysis $[9,10,14-22]$. The study selection process is shown in the study flow diagram Figure 1 .

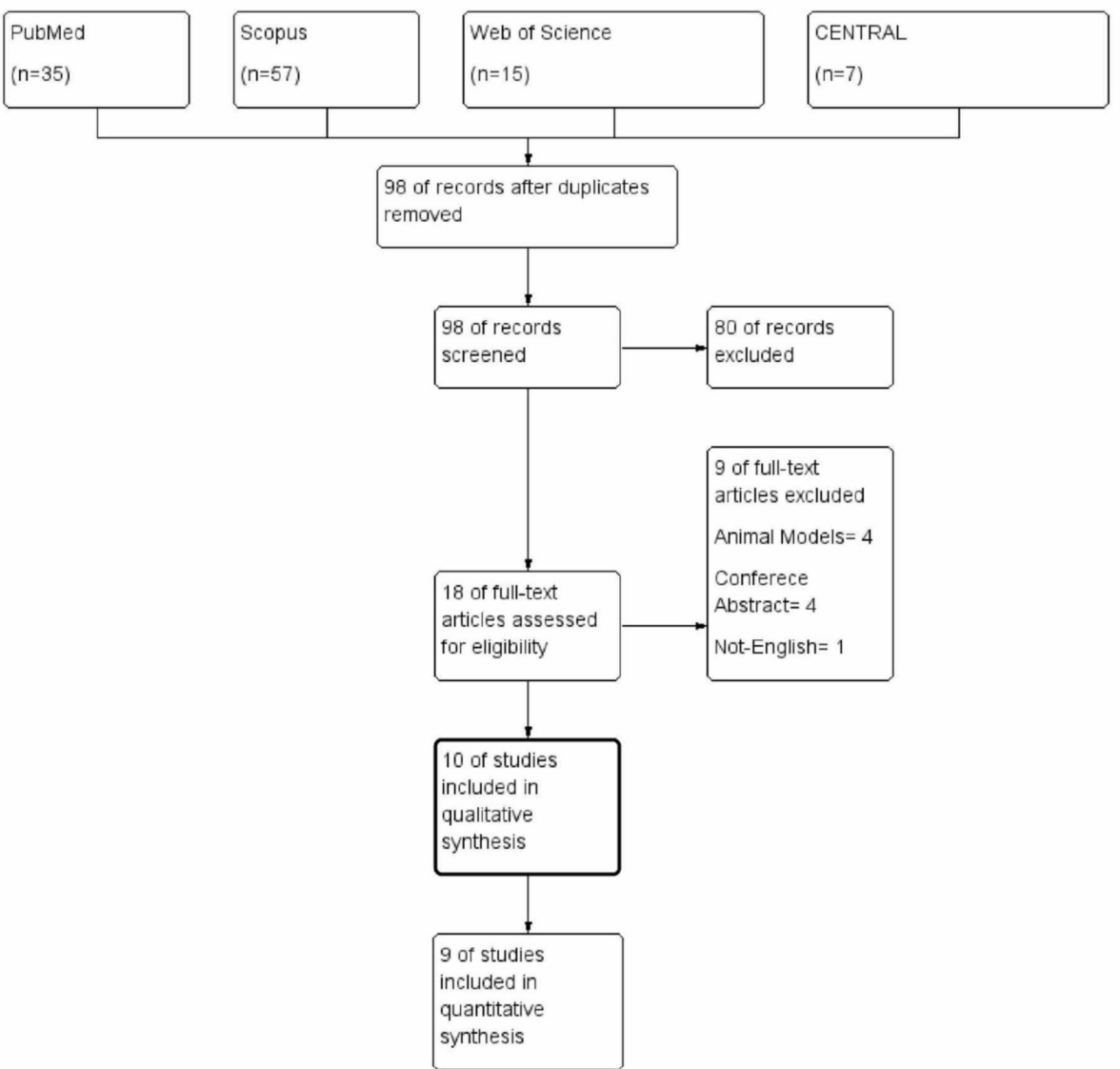

FIGURE 1: PRISMA flow diagram

PRISMA - Preferred Reporting Items for Systematic Review and Meta-Analysis; CENTRAL - Cochrane Central Register of Controlled Trials

\section{Demographic characteristics of included studies and individuals}

The majority of the included studies are from India (four studies) and Egypt (three studies). The other three studies are from Korea, Turkey, and the UK. The age of the included participants is ranging between two to 85 years. The number of patients with vitiligo was 1,181 and the control group was 1,559 . The summary of the included studies is presented in Table 1 , and the summary of the demographics and characteristics of included participants is presented in Table 2 . 


\section{Cureus}

\begin{tabular}{|c|c|c|c|c|}
\hline Study & Country & $\begin{array}{l}\text { Sample } \\
\text { size }\end{array}$ & PCR & Findings \\
\hline $\begin{array}{l}\text { Jin et al., } 2003 \\
\text { [21] }\end{array}$ & Korea & 549 & $\begin{array}{l}\text { Perkin-Elmer } \\
\text { GeneAmp } \\
\text { PCR }\end{array}$ & Significant association of D/D genotype and $\mathrm{D}$ allele with vitiligo. \\
\hline $\begin{array}{l}\text { Akhtar et al., } \\
2005[17]\end{array}$ & UK & 280 & PCR- RFLP & $\begin{array}{l}\text { No significant difference in the frequencies of } \mathrm{I} / \mathrm{I}, \mathrm{I} / \mathrm{D} \text { and } \mathrm{D} / \mathrm{D} \text { genotypes was } \\
\text { detected between vitiligo patients and control subjects }(\mathrm{p}=0.35) \text {. }\end{array}$ \\
\hline $\begin{array}{l}\text { Dwivedi et al., } \\
2008 \text { [20] }\end{array}$ & India & 250 & PCR & $\begin{array}{l}\text { ACE gene I/D polymorphism may not play a role in the development of } \\
\text { generalized vitiligo in Gujarat population. }\end{array}$ \\
\hline $\begin{array}{l}\text { Deeba et al., } \\
2009 \text { [22] }\end{array}$ & India & 387 & PCR & Significant association of D/D genotype and D allele with vitiligo. \\
\hline $\begin{array}{l}\text { Pehlivan et al., } \\
2009 \text { [14] }\end{array}$ & Turkey & 98 & PCR-RFLP & $\begin{array}{l}\text { No significant differences in either the genotype distribution or allele } \\
\text { frequencies of IL4, CCR5 and ACE gene polymorphisms were observed. }\end{array}$ \\
\hline $\begin{array}{l}\text { Tippisetty et } \\
\text { al., } 2010[15]\end{array}$ & India & 448 & PCR & Significant association of I/D genotype with slow progression. \\
\hline $\begin{array}{l}\text { Patwardhan et } \\
\text { al., } 2013 \text { [9] }\end{array}$ & India & 179 & PCR & $\begin{array}{l}\text { Serum ACE levels were significantly increased in patients with vitiligo } \\
\text { compared with healthy subjects }(p<0.0001) \text {. }\end{array}$ \\
\hline $\begin{array}{l}\text { Rashed et al., } \\
2015 \text { [10] }\end{array}$ & Egypt & 149 & PCR & ACE gene polymorphism might grant susceptibility to develop vitiligo. \\
\hline $\begin{array}{l}\text { Badran et al., } \\
2015[18]\end{array}$ & Egypt & 200 & $\begin{array}{l}\text { PCR- } \\
\text { GeneRuler }\end{array}$ & ACE gene polymorphism confers susceptibility to vitiligo. \\
\hline $\begin{array}{l}\text { Abdel Azeem } \\
\text { et al., } 2016[16]\end{array}$ & Egypt & 200 & $\begin{array}{l}\text { PCR- QIAamp } \\
\text { DNA mini Kit }\end{array}$ & $\begin{array}{l}\text { The frequencies of both } D \text { and I alleles for the ACE genetic marker were } \\
\text { significantly different between the control and patient populations }(p<0.001) \text {. }\end{array}$ \\
\hline \multicolumn{5}{|c|}{ ABLE 1: Summary of included studies } \\
\hline \multicolumn{5}{|c|}{$\begin{array}{l}\text { PCR - polymerase chain reaction; PCR- RFLP - polymerase chain reaction-restriction fragment length polymorphism; D/D - deletion/deletion; D/I } \\
\text { - deletion/insertion; I/I - insertion/insertion; ACE - angiotensin-converting enzyme }\end{array}$} \\
\hline
\end{tabular}




\section{Cureus}

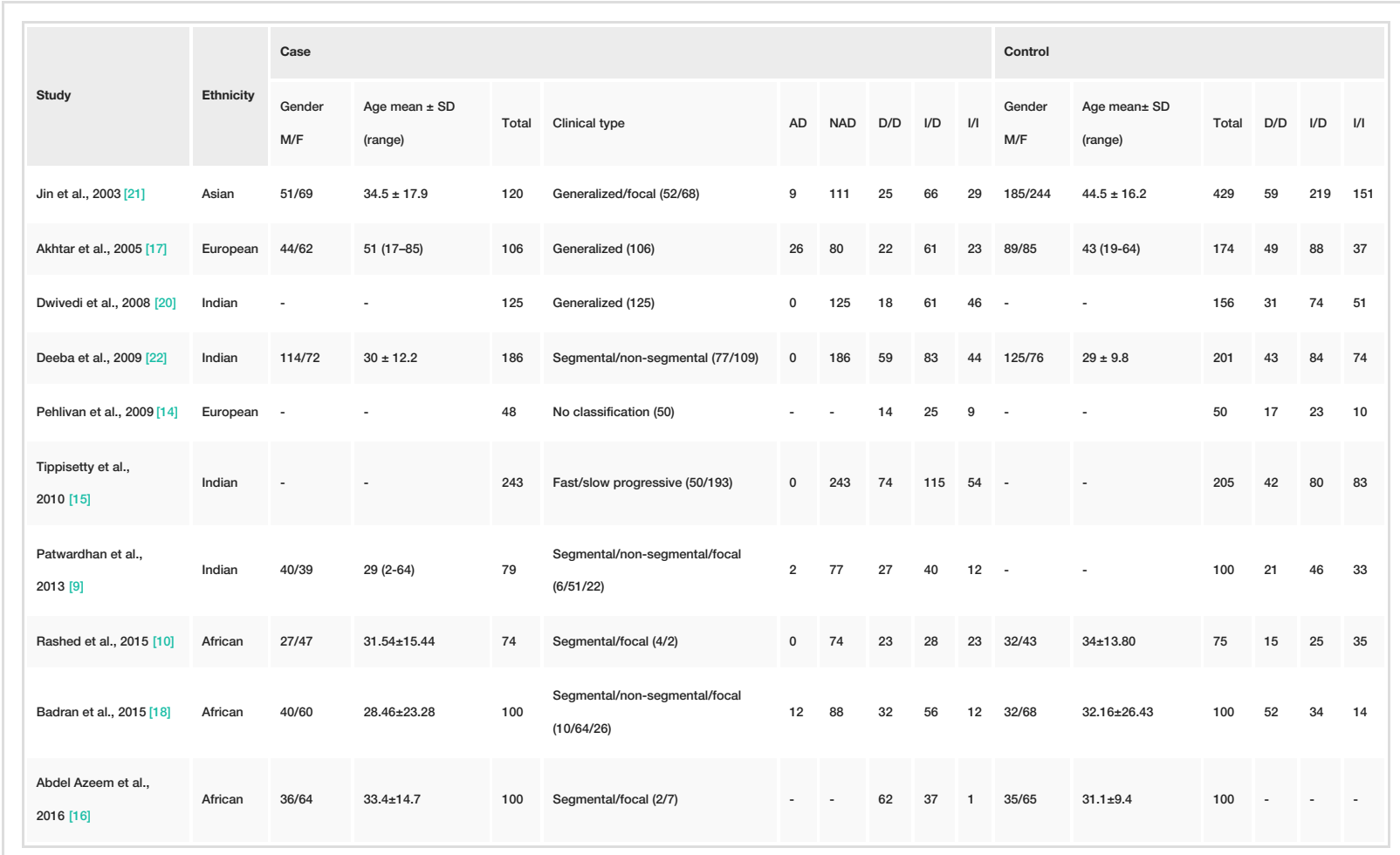

TABLE 2: Summary of included patients and the genotype distribution

SD - standard deviation; D/D - deletion/deletion; D/I - deletion/insertion; I/I - insertion/insertion

\section{D/D versus I/I + I/D (recessive model)}

The pooled analysis showed that there was no significant association between the deletion/deletion (D/D) versus insertion/insertion (I/I) + insertion/deletion (I/D) (recessive model) and vitiligo in random or fixed effect models ( $\mathrm{OR}=1.13,95 \%$ CI: 0.78 to $1.64, \mathrm{p}=0.53$; Figure 2 , or $\mathrm{OR}=1.18,95 \% \mathrm{CI}$ : 0.98 to 1.42 , $\mathrm{p}=0.09$, respectively). The pooled analysis was heterogenous $\left(\mathrm{I}^{2}=73, \mathrm{p}=0.0003\right)$. A sensitivity analysis was applied by removing Badran et al. [18], the effect size remained still non-significant ( $\mathrm{p}=0.11)$; however, the heterogeneity reduced to $\left(I^{2}=57, p=0.02\right)$, see Table 3 . According to the ethnic subgroup, there was a significant association between the recessive model and vitiligo in Asian populations - Indians and Koreans (OR= 1.49, 95\% CI: 1.08 to $2.05, \mathrm{p}=0.02)$ with homogenous data $\left(\mathrm{I}^{2}=45, \mathrm{p}=0.12\right)$. No significant association was observed in both Egyptians and Europeans ( $\mathrm{p}=0.84$ and $\mathrm{p}=0.15$, respectively). In patients with no associated autoimmune disease, a significant association between the recessive model and vitiligo was observed (OR=1.52, 95\% CI: 1.04 to $2.24, \mathrm{p}=0.03$ ) with homogenous data $\left(\mathrm{I}^{2}=0, \mathrm{p}=0.47\right)$. There was no significant difference among all types of vitiligo in terms of association with the recessive model.

\begin{tabular}{|c|c|c|c|c|c|c|c|c|c|c|c|}
\hline \multirow{2}{*}{$\begin{array}{l}\text { Study or Subgroup } \\
\text { Akhtar et al., } 2005\end{array}$} & \multicolumn{2}{|c|}{ Vitiligo } & \multicolumn{2}{|c|}{$\begin{array}{l}\text { Control } \\
\text { Events Total }\end{array}$} & \multirow{2}{*}{$\frac{\text { Weight }}{11.4 \%}$} & \multirow{2}{*}{$\begin{array}{c}\begin{array}{c}\text { Odds Ratio } \\
\text { M-H, Random, } 95 \% \mathrm{Cl}\end{array} \\
0.67[0.38,1.19]\end{array}$} & \multicolumn{5}{|c|}{$\begin{array}{c}\text { Odds Ratio } \\
\text { M-H, Random, } 95 \% \mathrm{Cl}\end{array}$} \\
\hline & 22 & 106 & 49 & 174 & & & & & & & \\
\hline Badran et al., 2015 & 32 & 100 & 52 & 100 & $11.4 \%$ & $0.43[0.24,0.77]$ & & & & & \\
\hline Deeba et al., 2009 & 59 & 186 & 43 & 201 & $12.7 \%$ & $1.71[1.08,2.70]$ & & & & & \\
\hline Dwivedi et al., 2008 & 18 & 125 & 31 & 156 & $10.8 \%$ & $0.68[0.36,1.28]$ & & & & - & \\
\hline Jin et al., 2003 & 25 & 120 & 59 & 429 & $12.0 \%$ & $1.65[0.98,2.77]$ & & & & & \\
\hline Patwardhan et al., 2013 & 27 & 79 & 21 & 100 & $10.4 \%$ & $1.95[1.00,3.81]$ & & & & & \\
\hline Pehlivan et al., 2009 & 14 & 48 & 17 & 50 & $8.6 \%$ & $0.80[0.34,1.88]$ & & & & & \\
\hline Rashed et al., 2015 & 23 & 74 & 15 & 75 & $9.6 \%$ & $1.80[0.85,3.82]$ & & & & & \\
\hline Tippisetty et al., 2010 & 74 & 243 & 42 & 205 & $12.9 \%$ & $1.70[1.10,2.63]$ & & & & & \\
\hline Total $(95 \% \mathrm{Cl})$ & & 1081 & & 1490 & $100.0 \%$ & $1.13[0.78,1.64]$ & & & & & \\
\hline Total events & 294 & & 329 & & & & & & & & \\
\hline $\begin{array}{l}\text { Heterogeneity: } \operatorname{Tau}^{2}=0.2 \\
\text { Test for overall effect: } Z=\end{array}$ & $\begin{array}{l}3 ; \mathrm{Ch}^{2}=2 \\
0.63(\mathrm{P}=\end{array}$ & $\begin{array}{l}9.32, d \\
0.53)\end{array}$ & If $=8(P=$ & & 3); $1^{2}=73 \%$ & & 0.1 & 0.2 & 0.5 & 2 & 5 \\
\hline
\end{tabular}

\section{FIGURE 2: Forest plot of the D/D versus I/I + I/D (recessive model)}

D/D - deletion/deletion; I/D - insertion/deletion; I/I - insertion/insertion; Cl - confidence interval, M-H - Mantel-Haenszel 


\section{$D / I$ versus $I / I+D / D$}

Observing $\mathrm{D} / \mathrm{I}$ versus $\mathrm{I} / \mathrm{I}+\mathrm{D} / \mathrm{D}$, pooled analysis showed a significant association with vitiligo whether by random or fixed effect models ( $\mathrm{OR}=1.29,95 \% \mathrm{CI}: 1.10$ to 1.52 , $\mathrm{p}=0.002$, Figure 3 , or $\mathrm{OR}=1.29,95 \% \mathrm{CI}: 1.10$ to 1.52, $\mathrm{p}=0.001$, respectively). The pooled analysis was homogenous $\left(\mathrm{I}^{2}=0, \mathrm{p}=0.58\right)$, see Table 3 . Ethnic subgroups showed a significant association between D/I versus I/I + D/D and vitiligo in the Egyptian population ( $\mathrm{OR}=1.83,95 \% \mathrm{CI}: 1.19$ to 2.83 , $\mathrm{p}=0.006)$. No significant association was observed in both Asians and Europeans ( $\mathrm{p}=0.07$ and $\mathrm{p}=0.20$, respectively). There was no significant association between $\mathrm{D} / \mathrm{I}$ versus $\mathrm{I} / \mathrm{I}$ $+\mathrm{D} / \mathrm{D}$ and vitiligo in both populations with/without autoimmune disease. Moreover, there was no significant difference among all subtypes of vitiligo in terms of association with $D / I$ versus I/I + D/D; however, the overall effect size showed a significant association with vitiligo as a whole $(\mathrm{OR}=1.27,95 \% \mathrm{CI}$ : 1.06 to $1.51, \mathrm{p}=0.008)$.

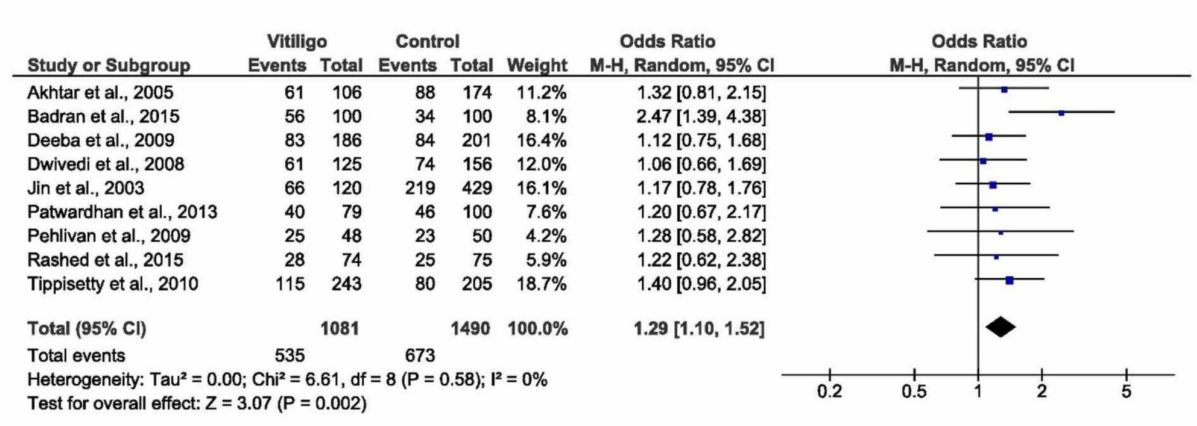

\section{FIGURE 3: Forest plot of the D/D + I/I versus D/I}

D/D - deletion/deletion; D/I - deletion/insertion; I/I - insertion/insertion; Cl - confidence interval, M-H - Mantel-Haenszel 


\section{Cureus}

\begin{tabular}{|c|c|c|c|c|c|}
\hline \multirow{2}{*}{ Comparison } & \multicolumn{3}{|c|}{ Test of association } & \multicolumn{2}{|c|}{ Heterogeneity } \\
\hline & OR & $95 \% \mathrm{Cl}$ & P-value & P-value & $\mathrm{I}^{2}(\%)$ \\
\hline \multicolumn{6}{|l|}{$D / D$ versus $I / I+I / D$} \\
\hline Fixed model & 1.18 & 0.98 to 1.42 & 0.09 & $<0.01$ & 73 \\
\hline Random model & 1.13 & 0.78 to 1.64 & 0.53 & 0.0003 & 73 \\
\hline Sensitivity analysis (Badran et al., 2015 [18]) & 1.29 & 0.94 to 1.77 & 0.11 & 0.02 & 57 \\
\hline \multicolumn{6}{|l|}{ I/D + D/D versus I/I } \\
\hline Fixed model & 1.60 & 1.33 to 1.92 & $<0.00001$ & 0.03 & 53 \\
\hline Random model & 1.55 & 1.17 to 2.06 & 0.002 & 0.03 & 53 \\
\hline Sensitivity analysis (Dwivedi et al., 2008 [20]) & 1.74 & 1.37 to 2.21 & $<0.00001$ & 0.23 & 25 \\
\hline \multicolumn{6}{|l|}{$D / /$ versus $D / D+1 / 1$} \\
\hline Fixed model & 1.29 & 1.10 to 1.52 & 0.001 & 0.58 & 0 \\
\hline Random model & 1.29 & 1.29 to 1.52 & 0.002 & 0.58 & 0 \\
\hline \multicolumn{6}{|l|}{ D/D vs I/I } \\
\hline Fixed model & 1.67 & 1.33 to 2.09 & $<0.0001$ & 0.001 & 69 \\
\hline Random model & 1.54 & 1.00 to 2.37 & 0.05 & 0.001 & 69 \\
\hline \multicolumn{6}{|l|}{ D versus I allele } \\
\hline Fixed model & 1.29 & 1.15 to 1.45 & $<0.0001$ & $<0.0001$ & 77 \\
\hline Random model & 1.24 & 0.97 to 1.59 & 0.08 & $<0.0001$ & 77 \\
\hline Sensitivity analysis (Dwivedi et al., 2008 [20] and & 1.45 & 1.18 to 1.77 & 0.0003 & 0.03 & 56 \\
\hline
\end{tabular}

\section{TABLE 3: Summary of a meta-analysis of ACE I/D polymorphism with vitiligo risk}

D/D - deletion/deletion; I/D - insertion/deletion; I/I - insertion/insertion; D/I - deletion/insertion; ACE - angiotensin-converting enzyme; OR - odds ratio; $\mathrm{Cl}$ - confidence interval

\section{D/D and I/D versus I/ (dominant model)}

Regarding the dominant model, the pooled analysis demonstrated a significant association with vitiligo whether by random or fixed effect models ( $\mathrm{OR}=1.55,95 \% \mathrm{CI}: 1.17$ to $2.06, \mathrm{p}=0.002$, Figure 4 or $\mathrm{OR}=1.60,95 \%$ CI: 1.33 to 1.92$), \mathrm{p}<0.00001$, respectively). The pooled analysis showed moderate heterogeneity ( $\mathrm{I}^{2}=53$, $\mathrm{p}=0.03$ ). Heterogeneity was unraveled by performing a sensitivity analysis removing Dwivedi et al., [20] study $\left(\mathrm{I}^{2}=23, \mathrm{p}=0.23\right)$, see Table 3 . According to the ethnic subgroup analysis, there was a significant association between the dominant model and vitiligo in the Asian populations - Indians and Koreans ( $\mathrm{OR}=$ $1.74,95 \%$ CI: 1.18 to $2.56, \mathrm{p}=0.005)$, with moderate heterogeneity $\left(\mathrm{I}^{2}=68, \mathrm{p}=0.02\right)$. No significant association was observed in both Egyptians and Europeans ( $\mathrm{p}=0.08$ and $\mathrm{p}=1.00$, respectively). There was no significant association between the dominant model and vitiligo in both populations with/without autoimmune disease. Moreover, there was no significant difference among all subtypes of vitiligo in terms of association with the dominant model; however, the overall effect size showed a significant association with vitiligo in general $(\mathrm{OR}=1.63,95 \% \mathrm{CI}: 1.10$ to $2.41, \mathrm{p}=0.02)$. 


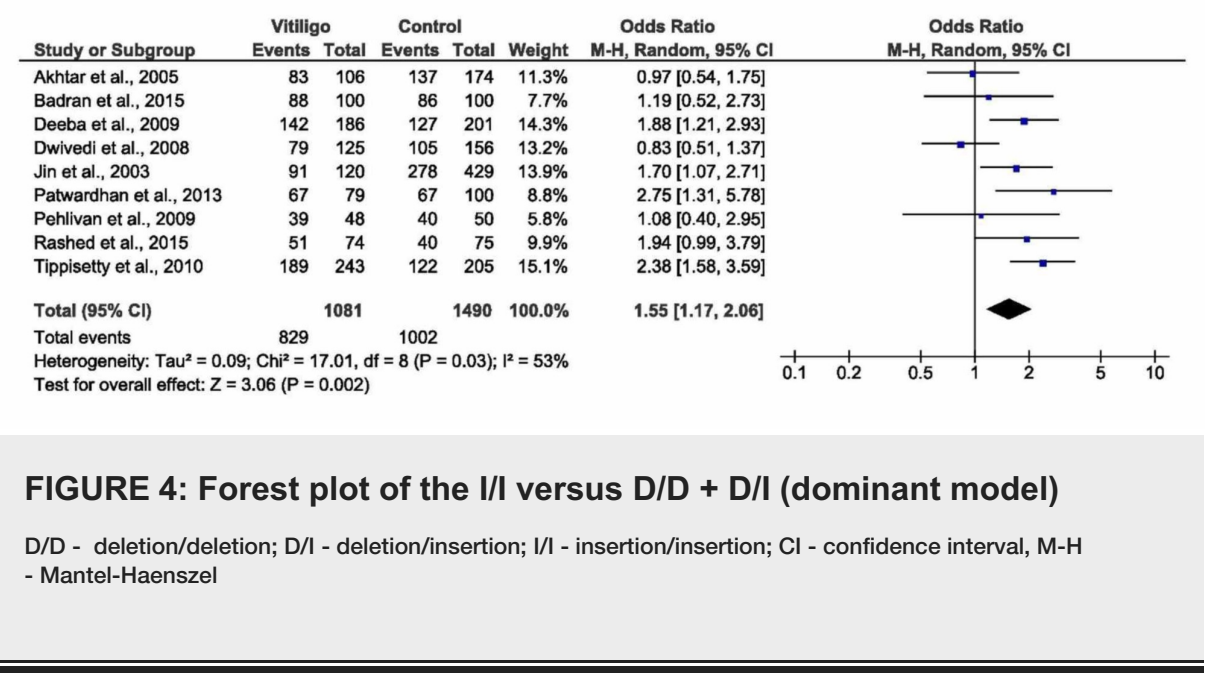

\section{Homozygous (D/D versus I/)}

The random model of the pooled analysis showed no significant association between homozygous genotypes and vitiligo ( $\mathrm{OR}=1.54,95 \% \mathrm{CI}: 1.00$ to 2.37 , $\mathrm{p}=0.05$, Figure 5). While in the fixed effect model, a highly significant association was observed ( $O R=1.67,95 \%$ CI: 1.33 to 2.09 , $\mathrm{p}<0.0001$ ). The pooled analysis demonstrated moderate heterogeneity $\left(I^{2}=69, p=0.001\right)$, which was not solved by sensitivity analysis, see Table 3. Ethnic subgroup analysis showed a significant association between homozygous genotypes and vitiligo in the Asian populations - Indians and Koreans ( $\mathrm{OR}=1.99,95 \% \mathrm{CI}: 1.19$ to 3.33, $\mathrm{p}=0.008$ ). No significant association was observed in both Egyptians and Europeans ( $\mathrm{p}=0.65$ and $\mathrm{p}=0.41$, respectively). There was no significant association between homozygous genotypes and vitiligo in both populations with/without autoimmune disease. However, homozygous genotypes were associated with non-segmental vitiligo (OR=2.35, 95\% CI: 1.44 to 3.82 , $\mathrm{p}=0.0006$ ).

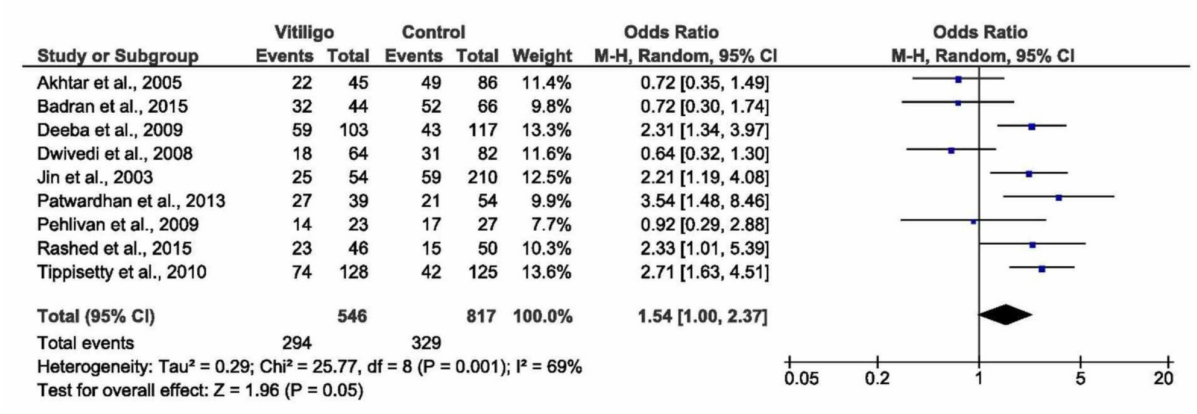

\section{FIGURE 5: Forest plot of the D/D versus D/l (homozygous model)}

$\mathrm{D} / \mathrm{D}$ - deletion/deletion; D/I - deletion/insertion; $\mathrm{Cl}$ - confidence interval, M-H - Mantel-Haenszel

\section{D allele versus I allele}

The random-effects model of the pooled analysis showed no significant association between D versus I alleles and vitiligo (OR=1.24, 95\% CI: 0.97 to 1.59, $\mathrm{p}=0.08$ ), Figure 6. While in the fixed effects model, a highly significant association was observed ( $\mathrm{OR}=1.29,95 \% \mathrm{CI}$ : 1.15 to $1.45, \mathrm{p}<0.0001)$. The pooled analysis demonstrated high heterogeneity $\left(\mathrm{I}^{2}=77, \mathrm{p}<0.0001\right)$, which was reduced by sensitivity analysis, see Table 3 . Ethnic subgroup analysis demonstrated a significant association between D vs I alleles and vitiligo in the Asian populations - Indians and Koreans ( $\mathrm{OR}=1.44,95 \% \mathrm{CI}$ : 1.10 to 1.89 , $\mathrm{p}=0.008$ ). No significant association was observed in both Egyptians and Europeans ( $\mathrm{p}=0.88$ and $\mathrm{p}=0.60$, respectively). There was no significant association between $\mathrm{D}$ vs I alleles and vitiligo in both populations with/without autoimmune disease. However, homozygous genotypes were once again associated with non-segmental vitiligo $(\mathrm{OR}=1.44,95 \% \mathrm{CI}$ : 1.07 to $1.95, \mathrm{p}=0.02$ ). 


\begin{tabular}{|c|c|c|c|c|c|c|c|c|c|c|}
\hline \multirow{2}{*}{$\begin{array}{l}\text { Study or Subgroup } \\
\text { Akhtar et al., } 2005\end{array}$} & \multicolumn{2}{|c|}{$\begin{array}{l}\text { Vitiligo } \\
\text { Events Total }\end{array}$} & \multicolumn{2}{|c|}{$\begin{array}{l}\text { Control } \\
\text { Events Total }\end{array}$} & \multirow{2}{*}{$\begin{array}{r}\text { Weight } \\
11.6 \%\end{array}$} & \multirow{2}{*}{$\begin{array}{c}\begin{array}{c}\text { Odds Ratio } \\
\text { M-H, Random, } 95 \% \mathrm{Cl}\end{array} \\
0.92[0.65,1.30]\end{array}$} & \multicolumn{3}{|c|}{$\begin{array}{c}\text { Odds Ratio } \\
\text { M-H, Random, } 95 \% \mathrm{Cl}\end{array}$} & \\
\hline & 109 & 212 & 186 & 348 & & & & & & \\
\hline Badran et al., 2015 & 120 & 200 & 138 & 200 & $10.5 \%$ & $0.67[0.45,1.02]$ & & & & \\
\hline Deeba et al., 2009 & 201 & 372 & 170 & 402 & $12.5 \%$ & $1.60[1.21,2.13]$ & & & & \\
\hline Dwivedi et al., 2008 & 97 & 250 & 136 & 312 & $11.7 \%$ & $0.82[0.58,1.15]$ & & & & \\
\hline Jin et al., 2003 & 116 & 240 & 337 & 858 & $12.4 \%$ & $1.45[1.08,1.93]$ & & & 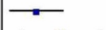 & \\
\hline Patwardhan et al., 2013 & 94 & 158 & 88 & 200 & $10.4 \%$ & $1.87[1.22,2.85]$ & & & & \\
\hline Pehlivan et al., 2009 & 53 & 96 & 57 & 100 & $8.4 \%$ & $0.93[0.53,1.63]$ & & & & \\
\hline Rashed et al., 2015 & 74 & 148 & 55 & 150 & $9.8 \%$ & $1.73[1.09,2.74]$ & & & & \\
\hline Tippisetty et al., 2010 & 263 & 486 & 164 & 410 & $12.7 \%$ & $1.77[1.36,2.31]$ & & & & \\
\hline Total $(95 \% \mathrm{Cl})$ & & 2162 & & 2980 & $100.0 \%$ & $1.24[0.97,1.59]$ & & & & \\
\hline Total events & 1127 & & 1331 & & & & & & & \\
\hline $\begin{array}{l}\text { Heterogeneity: } \mathrm{Tau}^{2}=0.1 \\
\text { Test for overall effect: } Z=\end{array}$ & $\begin{array}{l}\mathrm{Chi}^{2}=3 \\
72(\mathrm{P}=\mathrm{C}\end{array}$ & & $8(\mathrm{P}$ & 0.00 & 1); $\left.\right|^{2}=77$ & & 0.2 & 0.5 & $\begin{array}{l}1 \\
2\end{array}$ & 5 \\
\hline
\end{tabular}

\section{FIGURE 6: Forest plot of the D allele versus I allele}

$\mathrm{Cl}$ - confidence interval, M-H - Mantel-Haenszel

\section{Discussion}

The development of vitiligo can be processed by the action of ACE, which participates in degrading the substance $\mathrm{P}$ and peptide mediators [23-25]. The presence of substance P can induce many inflammatory reactions like mast cell and leukocyte activation, cytokines production, and plasma extravasation [26]. Moreover, ACE inactivates the bradykinin and the kallikrein-kinin system, which leads to significant implications in the inflammatory process [27].

To the best of our knowledge, this is the largest and most updated systematic review and meta-analysis that evaluated the association between vitiligo and ACE gene polymorphism. Our findings showed that there was no significant difference between the individuals carrying the D/D genotype and the individuals with D/I + I/I genotypes in the term of risk of vitiligo. On the other hand, the risk of vitiligo was higher in the individuals carrying the I/D when compared with individuals carrying D/D + I/I genotypes. Moreover, this risk was also observed in individuals carrying D/D when compared with I/I. D allele was associated with significant risk when compared with the I allele. Remarkably, the I/I genotype has a protective effect against the risk of vitiligo when compared with $\mathrm{D} / \mathrm{D}+\mathrm{D} / \mathrm{I}$ genotypes. Asian populations carrying the $\mathrm{D} / \mathrm{D}$ genotype and D allele have a higher risk of vitiligo when compared with other populations. Egyptians carrying the D/I genotype have a higher risk of vitiligo when compared with other populations. Furthermore, individuals carrying D/D genotype and D allele have a higher risk of non-segmental vitiligo when compared with other types of vitiligo. The observed significant heterogeneity can be explained by the variation between the studies in terms of vitiligo clinical classification, ethnicity, and associated diseases. These findings were supported by published data reporting D allele, and D/D and D/I genotypes associated with a higher risk of vitiligo, especially in Indian populations [9]. In addition, they observed that the serum level of ACE was significantly elevated in vitiligo patients compared with the control group.

Data from a previous meta-analysis reported a significant association between the recessive model and vitiligo $(\mathrm{p}<0.0001)[28]$. Moreover, they failed to find any association between $\mathrm{D} / \mathrm{I}$ genotype and vitiligo $(\mathrm{p}=0.24)$. This disagreement can be explained by the limited number of studies that they included. Besides, they did not perform a detailed subgroup analysis; they only classified their analysis to overall and generalized vitiligo.

One of the published case-control studies evaluated the distribution of ACE I/D gene polymorphism in the Egyptian population. They reported that the $\mathrm{D}$ allele was more distributed in vitiligo patients when compared with control $(\mathrm{p}<0.001)$ [14]. In contrast, the I allele was less distributed in vitiligo patients when compared with control $(\mathrm{p}<0.001)$. Moreover, they demonstrated that there was no significant difference between patients associated with or without other autoimmune diseases in terms of D/D, D/I, and I/I genotypes ( $\mathrm{p}=0.75$ ) and $\mathrm{D}$ and I alleles ( $\mathrm{p}=0.86$ and $\mathrm{p}=0.29$, respectively). In contrast, another Egyptian study suggested that individuals carrying the $\mathrm{D} / \mathrm{I}$ genotype have a higher risk of vitiligo when compared with $\mathrm{D} / \mathrm{D}+$ $\mathrm{I} / \mathrm{I}[16]$. This disagreement between both studies was most likely attributed based on the center of each study.

Despite this study's significant findings, there are some limitations. This study mainly relied on genetic factors for vitiligo without accounting for environmental factors. In addition, none of the included studies had detailed information about the patients with a family history of vitiligo, which is considered as a major contributor to the occurrence of vitiligo. Moreover, this study showed a significant heterogeneity; however, sensitivity and subgroup analyses were performed to mediate this heterogeneity.

\section{Conclusions}

In conclusion, the current evidence suggests that there is a significant association between ACE I/D gene 
polymorphism and vitiligo. This risk may be higher in some populations such as Egyptians and Indias when compared with Europeans. These findings support the use of ACE polymorphism in the prediction of vitiligo as a biomarker.

\section{Additional Information \\ Disclosures}

Human subjects: All authors have confirmed that this study did not involve human participants or tissue. Animal subjects: All authors have confirmed that this study did not involve animal subjects or tissue. Conflicts of interest: In compliance with the ICMJE uniform disclosure form, all authors declare the following: Payment/services info: All authors have declared that no financial support was received from any organization for the submitted work. Financial relationships: All authors have declared that they have no financial relationships at present or within the previous three years with any organizations that might have an interest in the submitted work. Other relationships: All authors have declared that there are no other relationships or activities that could appear to have influenced the submitted work.

\section{Acknowledgements}

The author would like to thank Dr. Malik Almohideb (Internal Medicine, Prince Sultan Military Medical City, Riyadh, Saudi Arabia), Dr. Hussein Ahmed (Faculty of Medicine, Zagazig University, Zagazig, Egypt), and Dr. Marwa Adel Afifi (Clinical Research, Integrative Medicine Company, Al Malqa, Riyadh, Saudi Arabia) for their help while conducting this meta-analysis.

\section{References}

1. Tham HL, Linder KE, Olivry T: Autoimmune diseases affecting skin melanocytes in dogs, cats and horses: vitiligo and the uveodermatological syndrome: a comprehensive review. BMC Vet Res. 2019, 15:251. 10.1186/s12917-019-2003-9

2. Allam M, Riad H: Concise review of recent studies in vitiligo . Qatar Med J. 2013, 2013:1-19. 10.5339/qmj.2013.10

3. Zhang Y, Cai Y, Shi M, et al.: The prevalence of vitiligo: a meta-analysis. PLoS One. 2016, 11:e0163806. 10.1371/journal.pone.0163806

4. Ezzedine K, Lim HW, Suzuki T, et al.: Revised classification/nomenclature of vitiligo and related issues: the Vitiligo Global Issues Consensus Conference. Pigment Cell Melanoma Res. 2012, 25:1-13. 10.1111/j.1755148X.2012.00997.x

5. Baldini E, Odorisio T, Sorrenti S, et al.: Vitiligo and autoimmune thyroid disorders . Front Endocrinol. 2017, 8:290. 10.3389/fendo.2017.00290

6. Blomhoff A, Helen Kemp E, Gawkrodger DJ, et al.: CTLA4 polymorphisms are associated with vitiligo, in patients with concomitant autoimmune diseases. Pigment Cell Res. 2005, 18:55-58. 10.1111/j.16000749.2004.00196.x

7. Al-Shobaili HA: Update on the genetics characterization of vitiligo . Int J Health Sci. 2011, 5:167-179.

8. Arora A, Kumaran M: Pathogenesis of vitiligo: an update. Pigment Int. 2017, 4:65-77. 10.4103/23495847.219673

9. Patwardhan M, Pradhan V, Taylor LH, et al.: The angiotensin-converting enzyme gene insertion/deletion polymorphism in Indian patients with vitiligo: a case-control study and meta-analysis. Br J Dermatol. 2013, 168:1195-1204. 10.1111/bjd.12177

10. Rashed L, Abdel Hay R, Mahmoud R, Hasan N, Zahra A, Fayez S: Association of angiotensin-converting enzyme (ACE) gene polymorphism with inflammation and cellular cytotoxicity in vitiligo patients. PLoS One. 2015, 10:e0132915. 10.1371/journal.pone.0132915

11. 11] Liberati A, Altman DG, Tetzlaff J, et al.: The PRISMA statement for reporting systematic reviews and meta-analyses of studies that evaluate health care interventions: explanation and elaboration. J Clin Epidemiol. 2009, 62:1-34. 10.1016/j.jclinepi.2009.06.006

12. Kim KW, Lee J, Choi SH, Huh J, Park SH: Systematic review and meta-analysis of studies evaluating diagnostic test accuracy: a practical review for clinical researchers-part I. General guidance and tips. Korean J Radiol. 2015, 16:1175-1187.

13. Higgins JPT, Green S: Cochrane handbook for systematic reviews of interventions . A John Wiley and Sons Ltd, Chichester; 2008.

14. Pehlivan S, Ozkinay F, Alper S, et al.: Association between IL4 (-590), ACE (I)/(D), CCR5 (Delta32), CTLA4 (+49) and IL1-RN (VNTR in intron 2) gene polymorphisms and vitiligo. Eur J Dermatol. 2009, 19:126-128. 10.1684/ejd.2008.0578

15. Tippisetty S, Ishaq M, Komaravalli PL, Jahan P: Angiotensin converting enzyme (ACE) gene polymorphism in vitiligo: protective and predisposing effects of genotypes in disease susceptibility and progression. Eur J Dermatology. 2011, 21:173-177. 10.1684/ejd.2011.1279

16. Abdel Azeem NE, Attallah DA, Hussein AA, Alzzubidi NAS: The angiotensin-converting enzyme insertion/deletion polymorphism of vitiligo in a population in upper Egypt: a hospital-based study. J Egypt Women's Dermatologic Soc. 2016, 13:129-132. 10.1097/01.EWX.0000481054.37701.f5

17. Akhtar S, Gavalas NG, Gawkrodger DJ, Watson PF, Weetman AP, Kemp EH: An insertion/deletion polymorphism in the gene encoding angiotensin converting enzyme is not associated with generalised vitiligo in an English population. Arch Dermatol Res. 2005, 297:94-98. 10.1007/s00403-005-0585-5

18. Badran DI, Nada H, Hassan R: Association of angiotensin-converting enzyme ACE gene polymorphism with ACE activity and susceptibility to vitiligo in egyptian population. Genet Test Mol Biomarkers. 2015, 19:258263. 10.1089/gtmb.2014.0326 
19. Krishnan R, Sekar D, karunanithy S, Subramanium S: Association of angiotensin converting enzyme gene insertion/deletion polymorphism with essential hypertension in south Indian population. Genes Dis. 2016, 3:159-163. 10.1016/j.gendis.2016.03.001

20. Dwivedi M, Laddha NC, Shajil EM, Shah BJ, Begum R: The ACE gene I/D polymorphism is not associated with generalized vitiligo susceptibility in Gujarat population. Pigment Cell Melanoma Res. 2008, 21:407-408. 10.1111/j.1755-148X.2008.00462.x

21. Jin SY, Park HH, Li GZ, et al.: Association of angiotensin converting enzyme gene I/d polymorphism of vitiligo in Korean population. Pigment Cell Res. 2004, 17 :84-86. 10.1046/j.1600-0749.2003.00105.x

22. Deeba F, Jamil K, Rabbani S, Waheed MA, Rao H: Association of angiotensin converting enzyme gene I/D polymorphism with vitiligo in South Indian population. Int J Med Med Sci. 2009, 1:009-012.

23. Song GG, Bae SC, Kim JH, Lee YH: The angiotensin-converting enzyme insertion/deletion polymorphism and susceptibility to rheumatoid arthritis, vitiligo and psoriasis: a meta-analysis. J Renin-AngiotensinAldosterone Syst. 2015, 16:195-202. 10.1177/1470320313478285

24. Najmi E, Bahbah EI, Negida A, Afifi A, Baratloo A: Diagnostic value of serum neuron-specific enolase level in patients with acute ischemic stroke; a systematic review and meta-analysis. Int Clin Neurosci J. 2019, 6:36-41. 10.15171/icnj.2019.08

25. Johar D, Ahmed SM, El. Hayek S, et al.: Diabetes-induced proteome changes throughout development. Endocr Metab Immune Disord Drug Targets. 2019, 19:732-743. 10.2174/1871530319666190305153810

26. Sharma P: Meta-analysis of the ACE gene in ischaemic stroke. J Neurol Neurosurg Psychiatry. 1998, 64:227230. 10.1136/jnnp.64.2.227

27. Taştan HB, Akar A, Orkunoğlu FE, Arca E, Inal A: Association of HLA class I antigens and HLA class II alleles with vitiligo in a Turkish population. Pigment Cell Res. 2004, 17:181-184. 10.1111/j.1600-0749.2004.00141.x

28. Lv Y, Lv Y, Li Q, Lei W, Luan Q, Gao T: Association of ACE gene I / D polymorphism with vitiligo: a metaanalysis. Arch Dermatol Res. 2013, 305:365-370. 10.1007/s00403-013-1315-Z 